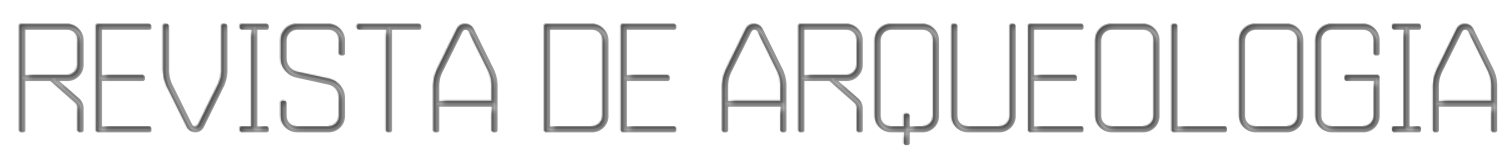

Volume 33 No. 2 Maio-Agosto 2020

\title{
ISSO NÃO É UM ARTIGO: DIALOGANDO COM IAN HODDER \\ SOBRE A VIRADA ONTOLÓGICA EM ARQUEOLOGIA
}

Marcio Teixeira-Bastos ${ }^{*}$, Lucio Menezes Ferreira*, lan Hodder ${ }^{\star \star \star}$

RESUMO

Trata-se de um diálogo com Ian Hodder sobre a virada ontológica em arqueologia. Debate-se sobre sua teoria sobre o Emaranhado Humano-Coisas e suas implicações sobre diversos temas: relações da arqueologia com outras ciências; agência das coisas; agência humana; poder; antropoceno e capitoloceno.

Palavras-chave: Teoria Arqueológica; ontologia; agência.

* Stanford University Visiting Scholar (2019-2020), com bolsa FAPESP (processo no 2018/18665-2). E-mail: marcioteixeirabastos@gmail.com. ORCID: https://orcid.org/0000-0002-3553-7129.

** UFPel. Bolsista de Produtividade do CNPq (1D). E-mail: luciomenezes@uol.com.br. ORCID: https://orcid.org/0000-0003-3147-2118.

*** Dunlevie Family Professor, Department of Anthropology, Stanford University; Director do Stanford Archaeology Center. E-mail: ihodder@stanford.edu. ORCID: https://orcid.org/0000-0002-7018586X. 


\section{THIS IS NOT A PAPER: DIALOGUING WITH IAN HODDER}

\section{ABOUT ONTOLOGICAL TURN IN ARCHAEOLOGY}

\section{ABSTRACT}

The following pages are a dialogue with Ian Hodder about the ontological turn in Archeology. It approaches his theory about the Human-Thing Entanglements and its implications on several subjects, such as the relations of Archeology and other sciences; agency of things; human agency; power; anthropocene and capitolocene.

Keywords: Archaeological Theory; ontology; agency.

\section{ESTO NO ES UN ARTÍCULO: DIALOGANDO CON IAN HODDER \\ EN TORNO AL GIRO ONTOLÓGICO EN ARQUEOLOGÍA}

\section{RESUMEN}

Las siguientes páginas constituyen un dialogo con Ian Hodder en torno al giro ontológico en arqueología. En ellas son debatidas su teoría sobre el Entrecruzamiento Humano-Cosas así como sus implicaciones sobre temas diversos: relaciones de la arqueología con otras ciencias; agencia de las cosas; agencia humana; poder; antropoceno y capitoloceno.

Palabras clave: Teoría Arqueológica; ontología; agencia. 
... El vino que pagué yo, Con aquel euro italiano,

Que había estado en un vagón,

Antes de estar en mi mano,

$Y$ antes de eso en Torino,

$Y$ antes de Torino, en Prato,

Donde hicieron mi zapato

Sobre el que caería el vino,

Zapato que en unas horas,

Buscaré bajo tu cama,

Con las luces de la aurora

Junto a tus sandalias planas,

Que compraste aquella vez,

En Salvador de Bahía,

Donde a otro diste el amor,

Que hoy yo te devolvería..

Cada uno da lo que recibe,

$Y$ luego recibe lo que da

Nada es más simples,

No hay otra norma,

Nada se pierde, Todo se transforma..

Jorge Drexler, Todo Se Transforma, 2004

\section{APRESENTAÇÃO: TRAVESSIA DE FRONTEIRAS}

Ian Hodder é bem conhecido no Brasil e alhures. No caso do Brasil, onde há, hoje, dezenas de cursos de graduação e pós-graduação em arqueologia, Hodder é referência obrigatória, principalmente em teoria arqueológica. Decerto, qualquer estudante de graduação ou pós-graduação em arqueologia já leu Hodder. De modo que não fará falta aqui uma apresentação mais cabal de sua obra. Nesse momento, talvez seja suficiente dizer que ele trabalha no Departamento de Antropologia da Escola de Humanidades e Ciências da Universidade de Stanford. Nessa mesma universidade, é diretor do Centro de Arqueologia. Hodder é também reconhecido internacionalmente por seu trabalho no sítio neolítico Çatalhöyük, localizado na Turquia (Figura 1).

Neste texto, dialogamos com Hodder sobre a virada ontológica em arqueologia, tema sobre o qual ele vem influindo na última década com sua teoria sobre o emaranhado humano-coisas. Antes de passarmos ao diálogo, cabem alguns comentários pontuais. Primeiro, esse diálogo provém do período em que estivemos nos Estados Unidos realizando pós-doutorado ${ }^{1}$. Tal oportunidade possibilitou que nos encontrássemos, e, dentre outros assuntos que conversamos, ocorreu-nos a ideia de debatermos com Hodder sobre as implicações de sua obra recente. A ideia foi maturada entre julho e outubro de 2019. A partir de contato pessoal com o Professor Hodder e das conversas que tivemos com ele, estruturamos questionamentos, com sua anuência e sempre gentil e animada colaboração. Oferecemos, pois, esse diálogo ao público, no intuito de contribuir com os debates sobre virada ontológica na arqueologia.

\footnotetext{
${ }^{1}$ Lúcio Menezes Ferreira, entre junho de 2018 e agosto de 2019, realizou pós-doutorado, com bolsa CNPq, no Afro-Latin American Research Institute da Universidade de Harvard e no Departamento de Antropologia da Illinois State Universiy, em ambos os locais sob a supervisão da Professora Kathryn Sampeck; Marcio Teixeira-Bastos realizou seu pós-doutorado, com bolsa FAPESP, entre janeiro de 2019 e janeiro de 2020, no Centro de Arqueologia da Universidade de Stanford, sob a supervisão do Professor Ian Hodder.
} 
Figura 1 - Área Sul das Escavações em 2015 no sítio arqueológico de Çatalhöyük. (Çatalhöyük Research Project). Imagens concedidas por Ian Hodder.
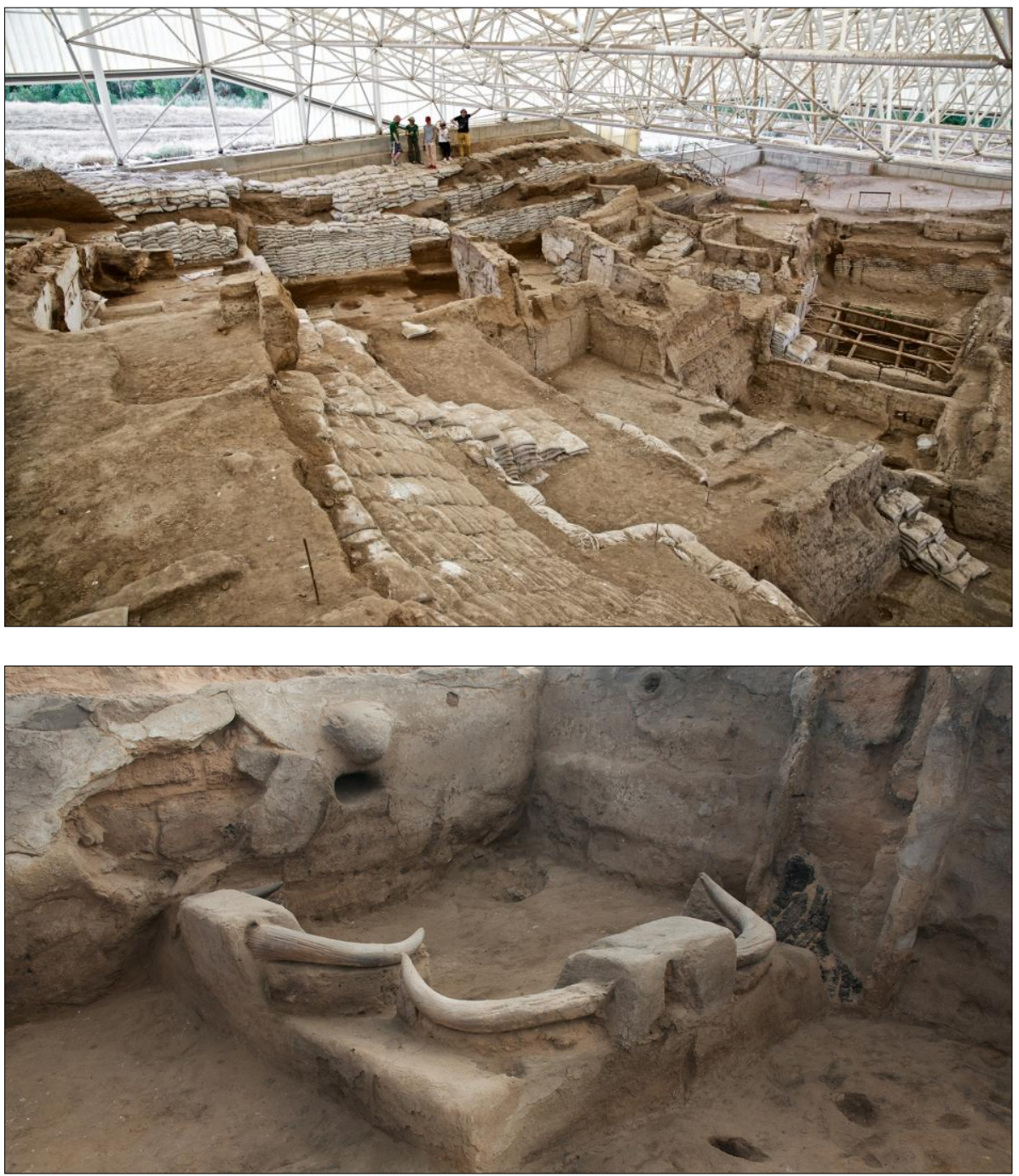

O diálogo, como se verá, atravessa fronteiras. Enseja, pelos menos, duas linhas de discussão, as quais frisamos aqui por não estarem tão diretamente enunciadas nas perguntas e respostas de nossa conversa. Certamente leitores e leitoras verão outros pontos para debate. A primeira fronteira percorrida é a da interdisciplinaridade. A multidirecional abordagem de Hodder tem importantes consequências para as fronteiras ainda rígidas das pesquisas acadêmicas. A virada ontológica, na teoria sobre o emaranhado humano-coisas de Hodder, leva-nos a investigar os fluxos e contrafluxos que ligam as coisas, pessoas, instituições e ideias. Incita-nos a pensar a partir do ponto de vista das coisas, segundo seus valores qualitativos. Assim, descobrimo-nos, para darmos somente um exemplo, abrindo novas veredas para a arqueometria, sem suas restrições epistemológicas tradicionais, quase sempre cientificistas. Nessa linha, a análise química do antiplástico e petrográfica da pasta (matriz) de uma cerâmica não nos diz somente sobre sua funcionalidade ou tipologia, e, logo, sobre as categorias funcionais de sítios arqueológicos. A escolha de um vegetal, animal ou mineral para a confecção da cerâmica nos conduz à inseparabilidade entre humanos e não humanos, mostrando-nos a riqueza particular de uma ontologia e de suas múltiplas existências possíveis.

Esse projeto arqueológico interdisciplinar vai além ao perguntar: quais são as ligações estabelecidas, hoje, entre arqueologia, física, química e biologia? Parte das 
questões respondidas por Hodder trafega sobre as diversas rotas que a arqueologia perfaz ao entabular discussões com a noção de Grande Realidade, com a teoria da complexidade, dos sistemas dinâmicos ou redes autopoiéticas. Hodder, contudo, enfatiza como a teoria do emaranhado humano-coisas, embora dialogue de frente com outras ciências, tem feição marcadamente histórica. Aqui reside a segunda fronteira atravessada, a da temporalidade, aquela que borra a divisão historicista entre passado e presente. Hodder procura interrogar nossas práticas em suas mais antigas camadas; vasculha nossas relações com as coisas e das coisas conosco, na senda da longa duração e de historicidades enramadas em multitemporalidades.

Um último comentário: esse texto não é mesmo um artigo! O título é livremente inspirado na pintura a óleo de René Magritte (1929), A Traição das Imagens, na qual um simples cachimbo desestabiliza nosso solo tropológico, dizendo-nos: "isso não é um cachimbo" (Figura 2). Magritte nega, como mostra Foucault (1988), a pretensão realista da representação, ou o regime linguístico que consubstancia imagem e coisa em si. Um cachimbo, como qualquer tipologia, só é compreensível quando o esgarçamos até rompêlo como simples categoria única, envolvendo-o nas diferentes maneiras pelas quais coisas e pessoas se enlaçam. De outro lado, o título provoca a experimentação de outras formas de pensar e escrever arqueologia. É uma tentativa de tornar as discussões em teoria arqueológica, talvez, menos áridas e mais dialógicas, de experimentar narrativas cuja retórica embale no mesmo enredo as multitemporalidades que ligam passado e presente (GONZÁLEZ RUIBAL, 2012), sem confiná-las na linearidade de uma prosa sem sabor (VANDYKE; BERNBECK, 2015). É certo que os diálogos, como forma literária e filosófica, têm a idade de Platão, mas é certo também que antigo e moderno sempre se reativam, enredando-nos.

Figura 2 - René Magritte. La Trahison des Images (1929), óleo sobre Tela $(63,5$ x 93,8). Fonte: https://magritte.brussels/index.php/portfolio/la-trahison-des-images-1928-29/. Acesso em 15/12/2019.

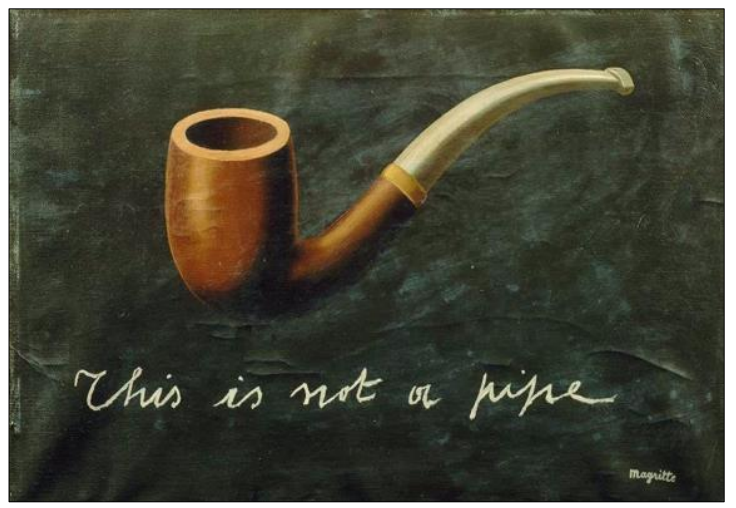

\section{O DIÁLOGO²}

MTB e LMF - Seu livro Symbols in Action (1982) é um marco do pensamento arqueológico. Nessa obra, a partir de detalhado trabalho etnoarqueológico na África e retomando discussões já enunciadas em The Spatial Organisation of Culture (1978), você delineou dois problemas que ainda orientam os debates contemporâneos, mesmo que essa orientação seja, agora, contrapontística: a relação entre cultura material, contexto e significado; e a relação entre cultura material e ação social. Você também tratou esses

\footnotetext{
${ }^{2}$ Não custa avisar que nossas perguntas são precedidas por nossas iniciais, MTB e LMF, valendo o mesmo para as respostas do Professor Ian Hodder, IH.
} 
problemas em duas obras de síntese teórica: uma lançada no mesmo ano de Symbols in Action, intitulada Symbolic and Structural Arqueology (1982), e outra, quatro anos depois, com o sugestivo título Reading the Past (1986). Você deixa claríssimo, em mais de um capítulo do seu The Archaeological Process (1999), que se acercou desses problemas com os princípios da hermenêutica, uma vez que ressaltou a polissemia, os deslocamentos contextuais, os diferentes significados ditados pelas escalas temporais e espaciais da cultura material. Acercou-os também com a teoria social moderna, especificamente com a noção de estruturação da ação social: grupos e indivíduos, de forma consciente ou inconsciente, se valem da cultura material para construir o mundo, negociar posições, interferir nos processos de mudança social e nas relações de poder e dominação. Indivíduos e grupos arregimentam o poder simbólico, isto é, usam a linguagem da cultura material - e seria mais apropriado usar o plural, as linguagens da cultura material - como estratégia de controle social, de legitimação política, de enfrentamento e resistência. A cultura material, assim, não reflete passivamente a sociedade, mas a cria por meio da ação de indivíduos, coletivos e instituições. Nessa acepção, a arqueologia, como diriam Michael Shanks e Christopher Tilley (1982), estuda o poder. Para dizê-lo de outro modo, esses problemas derivam da ideia de que a linguagem é paradigma do humano, do antropocentrismo advindo da revolução copernicana de Kant em que a ontologia redunda do epistêmico e do categorial.

Mais recentemente houve uma virada em seu pensamento. Um giro ontológico, como o chamamos aqui nesse diálogo contigo. O argumento geral de seus últimos livros (HODDER, 2012, 2016, 2018) é que as experiências materiais e humanas são inelidíveis e possuem múltiplos e recursivos efeitos; as coisas não são sociotransmissores das sociedades humanas; e, embora as coisas unam as pessoas ao longo do tempo, promovendo a estabilidade, a continuidade e os processos de mudança da vida social, elas são indisciplinadas, difíceis de governar ou, mesmo, ingovernáveis. As coisas criam a dependência humana. Não obedecem plenamente ao regime dos tropos. Como você explica essa virada em seu pensamento? Quais são os condutos que ligam sua obra recente aos problemas levantados desde Symbols in Action? Há um deliberado abandono da linguagem como paradigma da relação humano-coisas? Como, doravante, a arqueologia deve estudar o poder? O ponto central seria o estudo das tensões assimétricas, da coconstituição dialética das relações humanos-coisas? O descentramento do humano implicaria abordagens sobre coalizões cosmopolíticas, pautadas em descrições sobre as continuidades e descontinuidades entre humanos e coisas?

IH - Nos anos 1990, como vocês bem notaram, eu já escrevera sobre os limites do modelo linguístico para o estudo da cultura material. O principal problema parecia ser que, embora se possa dizer que muitas coisas materiais, como bandeiras ou insígnias de realeza, têm uma clara função semiótica, muitas outras coisas fazem mais do que sinalizar ou simbolizar. A maioria das coisas está embebida numa série de práticas, de tal maneira que, por exemplo, um pote faz muito mais do que a palavra pote. É este "muito mais" que precisa ser explorado. Obviamente muitos antropólogos desenvolveram teorias sobre a agência da cultura material, mas elas me parecem problemáticas, pois aparentemente se desviam das coisas mesmas para concentrarem-se mais nas estratégias sociais utilizadas para manipulá-las. Meu deslocamento para a teoria do emaranhado humano-coisas como forma de capturar o "muito mais" adveio de duas direções. Uma delas proveio de minhas escavações no sítio neolítico Çatalhöyük, localizado na Turquia. Os dados filigranados desse sítio ajudaram-me a ver os modos pelos quais humanos e coisas foram emaranhados de maneiras assimétricas e dinâmicas. A outra direção foi Bruno Latour e suas ideias sobre a Teoria do Ator-Rede (TAR). Embora eu rejeite a noção de simetria entre humanos e coisas, penso que a TAR tem sido enormemente útil para a construção 
de uma linguagem por meio da qual podemos falar sobre as coisas como tendo uma agência quase independente na vida social. Essa é uma agência diferente daquela que descrevi em Symbols in Action, à medida que é tanto material quanto social. A agência na teoria dos emaranhados biomateriais tem múltiplas fontes, mas eu ainda argumentaria que, quer trabalhem na ciência material ou nos domínios do significado e da linguagem, e por mais relacionais que sejam, arqueólogos se valem de alguma forma do processo hermenêutico reflexivo de inferência.

Sobre o estudo do poder, sim, o principal ponto é focar-se nas relações assimétricas entre humanos e coisas. Os emaranhados biomateriais consistem de múltiplos fios estendidos no tempo. Arqueólogos conhecem esse emaranhamento como cadeias operatórias, padrões de comportamento e assim por diante. Esses emaranhados devem esperar uns pelos outros e dependem uns dos outros. O poder depende da habilidade de manipular e controlar esses processos; ou, antes, o poder emerge como potencial no interior dos emaranhados entre humano e coisas. O poder não é função numa rede, mas, sim, assimetrias no interior do emaranhado humano-coisas, o fato de que diferentes fios devem esperar uns pelos outros, dependem uns dos outros. Assim, os humanos são atrapados em particulares fluxos e contrafluxos nos quais encontram dificuldade para escapar. Um bom exemplo disso é a armadilha da pobreza. Não basta lidar com a pobreza aumentando a renda. Lidar com a pobreza envolve também educação, moradia, saúde, raça, gênero etc. Os diferentes fios ou fluxos são capturados uns pelos outros, de modo que a mobilidade social se torna extremamente rara.

MTB e LMF - Em Negara, Clifford Geertz (1980) disse que as críticas à antropologia contextual, a noção de que a cultura é uma rede de significados tecida com os fios da linguagem, noção tributária da sociologia weberiana e da filosofia de Wittgenstein, não passavam, segundo ele, de temores oitocentistas de "fantasmas metafísicos". Pode dizer-se que essas críticas se norteiam também pelo dualismo típico do Ocidente, provindo da filosofia clássica, entre doxa e episteme, materialismo e idealismo, essência e aparência, substância e acidente, imanência e transcendência. A virada ontológica tem a intenção manifesta de romper com todos esses maniqueísmos, principalmente entre epistemologia e ontologia, entre humanos e não humanos, humanos e coisas. Nessa acepção, o modelo hilomórfico da filosofia clássica, fundado na dualidade entre forma e matéria, não dá conta da perpetuidade dos processos de formação das materialidades e das relações contínuas entre elas e humanos. Humanos e coisas possuem imanência, e ambos se entrelaçam perenemente. Nessa linha, o antropólogo brasileiro Viveiro de Castro (2012) tem afirmado que a metafísica se tornou novamente uma ocupação respeitável. Daí o crescente interesse pelos não humanos, pela materialidade do mundo, pela ação social das coisas e um certo enfado com a linguística e a semiologia. A seu modo de ver, como a arqueologia contribui para essa reafirmação da metafísica? Uma vez que estuda a materialidade, a arqueologia, com relação às humanidades, teria maiores condições de, ao descentrar o humano, reaproximá-lo das coisas e do mundo vivo em geral? Se as coisas não são epifenômenos das sociedades, caberia à arqueologia o projeto de radicalizar a noção de que o pensamento se instaura na alteridade e no relacional, na realidade sensível de transação entre humanos, não humanos e as coisas? E se levarmos em conta a multiplicidade de processos que interconectam a chamada Grande Realidade, esse conjunto não seria tão "sistêmico", tão altamente complexo, que estaria fora do domínio da maioria dos humanos? 
IH - Junto com um professor de física, comecei a ensinar em Stanford uma disciplina chamada Matéria e Materialização ${ }^{3}$. Indubitavelmente influenciados por escritores como Karen Barad (2007), passamos grande parte das aulas ponderando a natureza da matéria, sobre o que mantém as coisas juntas, e perguntamos se as coisas realmente existem. Penso que uma das implicações mais empolgantes das mudanças ontológicas é o potencial de diálogo com a física teórica, bem como, de fato, com novas direções na biologia e na química. Parece que há interesses convergentes nas maneiras pelas quais o biológico, o material, o cultural e o social se entrelaçam. Comecei a escrever recentemente (como se vê em Where are we heading? ${ }^{4}, 2018$ ) sobre os emaranhados biossociomateriais. Estou empolgado com a ideia de que a matéria é apenas uma força e que nossa tarefa é entender essas forças e como elas se intersectam. Para mim, isso implica evitar uma noção abstrata de alto nível acerca dos sistemas complexos; ao contrário, envolve explorar os detalhes concretos de fluxos de energia específicos à medida que eles se formam nos emaranhados biomateriais.

MTB e LMF - Um conceito central da contemporaneidade, a perpassar todas as ciências, é o de antropoceno, conceito recente lançado pelo prêmio Nobel em química Paul Crutzen (2002). A premissa é que a humanidade, em sua relacionalidade imanente com as coisas, intensificada com a produção industrial da cultura de massa, tornou-se uma força geológica. Mais precisamente: a humanidade tornou-se uma força destrutiva sem precedentes. Alterou o planeta de tal forma, em escala tão global, com impactos geofísicos e biológicos tão amplos, que as previsões mais otimistas anunciam escassez de água e alimentos, novas doenças infecciosas, migração massiva e recrudescimento de conflitos regionais. Aqui se escuta a língua da tragédia grega, proclamando o pior, o fatal, a catástrofe, o escatológico, sem apresentar, contudo, qualquer solução axiológica, catarse ou redenção moral. Esse fenômeno tem apurado o gosto pela distopia, por uma espécie de ficção especulativa cujas narrativas sobre a hipermodernidade, sejam elas literárias ou cinematográficas, descrevem a humanidade sendo tragada pela inteligência artificial, a robótica, a mecatrônica. Nesse cenário antropocênico, humanos se tornam híbridos computadorizados, o corpo humano se robotiza, mesclando-se a chips e memórias artificiais, internalizando e naturalizando um autoritarismo cibernético, no qual satélites, câmeras, senhas e dispositivos diversos instauram um estado policial, de vigilância e controle perpétuos. Esse pesadelo autoritário faz as obras de Huxley, Kafka e Bradbury parecerem literatura infantil, e 2001, Uma Odisseia no Espaço, uma mera viagem transcendental regada a alucinógenos.

Deleuze prognosticou essa sociedade de controle permanente: a cada instante, tecnologias diversas localizando um elemento no espaço aberto, "animal numa reserva", humanos com coleira eletrônica. Outro cenário antropocênico é o império da sucata. Trata-se de um mundo repleto de "tecnofósseis": resíduos de plástico, concreto fragmentado, partículas de alumínio, fuligem e cinzas de combustíveis, em suma, uma pletora de materiais artificiais a formar "registros arqueológicos" e camadas sedimentares na terra e oceanos. O antropoceno, qualquer que seja o cenário distópico vislumbrado, aponta para o mundo pós-humano, em que objetos, resíduos artificiais, fuligens e máquinas serão nossos herdeiros evolucionários. A linguagem do mundo pós-humano é

\footnotetext{
${ }^{3}$ Matter and Mattering. O conceito de materialização (Mattering), enquanto extensão, se espraia em múltiplas direções. Engloba as lutas pessoais e geopolíticas, bem como as percepções e sensibilidades humanas mais íntimas, incluindo-se mesmo a ilusão ou o desespero. A materialização é a concretização cabal da relacionalidade entre humanos e não humanos, por meio da qual nossas cosmologias são formadas. A teoria da matéria procura descrever a estrutura que fundamenta a evolução do humano em sua relação inextricável com as coisas.

4 Tradução: Para onde estamos indo?
} 
feita de oximoros, de paradoxos, pois, no final das contas, parece que o sufixo pós não significa propriamente futuro, não é uma ruptura radical com o passado, mas, sim, uma recapitulação crítica da modernidade tardia. O humano, suas ações e novas formas de tecnologia são severamente criticadas, críticas cuja tônica remonta minimamente à chamada Escola de Frankfurt e à literatura filosófica pós II Guerra Mundial, tanto europeia (Hanna Arendt, Ernst Cassirer, Elias Canetti) quanto caribenha (Aimé Césaire e Frantz Fanon). O pós-humano antropocênico radicaliza a crítica ao modelo humanista liberal, iluminista, no intuito de reconstruir e refundar o humanismo. Para abusar do oximoro, é como disseram, na obra Império, Antonio Negri e Michael Hardt (2000): o novo humanismo há de ser pós-humanista. Ao seu modo de ver, como a arqueologia, disciplina das coisas e das técnicas por excelência, pode contribuir com essa crítica póshumanista?

IH - Eu discordo do termo antropoceno, e vocês o abordaram de uma maneira muito ampla e generosa, como se fosse uma nova etapa. Se alguém está falando sobre o impacto humano no clima e no meio ambiente, ou sobre o surgimento de ciborgues, parece-me que os humanos sempre dependeram das coisas de maneira semelhante. Cientistas como Neil Roberts argumentam que, pelo menos desde o Paleolítico, estamos mudando o ambiente, e eu argumentei (em Where are we heading?, 2018) que os humanos sempre dependeram de coisas e tecnologias para resolver seus problemas. É por isso que há uma direcionalidade na evolução das coisas humanas. A dependência das coisas humanas não é uma coisa nova, é o que significa ser humano e, portanto, somos sempre atraídos para uma dependência ainda maior das coisas. Muitas soluções sugeridas hoje para lidar com as mudanças climáticas, o consumismo desenfreado e a corrida para as tecnologias envolvem ainda mais dependência das coisas. Nosso papel como arqueólogos poderia ser chamar a atenção para modos de vida alternativos. É claro que existem movimentos sociais atuais como aqueles que propõem estilos de vida minimalistas, e seria possível aos arqueólogos reforçar esses movimentos chamando a atenção para outras formas de viver com as coisas, muitas vezes informadas pelos conhecimentos tradicionais indígenas.

MTB e LMF - Gostaríamos de insistir nesse tema do antropoceno e suas relações com a pobreza e a política. Em seu livro Studies in Human-Thing Entanglement (2016) você reproduziu um debate ocorrido em Berlim, em 2013, que sumarizou diversas críticas ao seu trabalho recente, algumas delas muito duras, a exemplo de que sua teoria carece de uma posição política explícita. Talvez seja oportuno retomarmos essa discussão, até mesmo porque seu último livro, Where are we heading? (2018), pode ser visto como uma obra de filosofia política formulada a partir da arqueologia. Você argumenta que o ser humano depende de outros seres humanos e das coisas; as coisas, por sua vez, dependem dos seres humanos; e, por fim, as coisas dependem de outras coisas. Assim, o emaranhamento humano-coisas pode ser definido como dialética das dependências e subalternizações entre seres humanos e coisas. Nos emaranhados biomateriais há processos de captura, fluxos e contrafluxos que enlaçam e abrangem seres humanos, animais, coisas, ideias e instituições. Tal argumento nos permite pensar os diferentes regimes de poder que nos aprisionam materialmente. Obviamente, e você já o deixou claro no capítulo cinco de seu Studies in Human-Thing Entanglement (2016), os aprisionamentos atingem mais aos pobres, aos marginalizados e, acrescentaríamos nós, afetam mais cruelmente as populações que ainda vivem sob estruturas coloniais e racistas.

Temos aqui um problema de escala global. Nem todos estão aprisionados do mesmo modo. Outra maneira de dizê-lo é que as estruturas coloniais e racistas confinam populações inteiras a um regime material que podemos caracterizar como bifronte. De um lado, a escassez material, a carência de recursos. A obra da escritora negra Carolina 
Maria de Jesus, uma mulher que viveu numa favela de São Paulo a maior parte de sua vida (ela morreu em 1977), mostra à exaustão o que é viver sob carência material extrema (Figura 3). Trabalhando como catadora de fragmentos de ferro e papel para reciclagem, ela sabia bem como era viver das coisas que sobram, dos materiais descartados. Daí, talvez, sua definição de favela como lixeira da cidade grande. Nesse ponto, é irresistível não pensar Carolina como arqueóloga. Afinal, boa parte do trabalho arqueológico é reflexão sobre lixeiras e materiais reciclados. De outro lado, esse regime prima pela abundância material. Como catadora de papel, Carolina Maria de Jesus circulava cotidianamente pelo centro de São Paulo, e sua experiência urbana a leva a descrever a monumentalidade da cidade, sua distribuição desigual de recursos, os bairros ricos e restaurantes frequentados por brancos, as diferentes paisagens e coisas que a aprisionavam numa estrutura racista. A experiência de Carolina se reproduz, com variações, em várias partes do mundo. As estatísticas oficiais enfatizam que $46 \%$ da população mundial vive abaixo da linha da pobreza. Para essas populações é válida uma ironia de Carolina: a única coisa em excesso na favela é a lama, sobre a qual ela e suas três crianças eram obrigadas a pisar durante o inverno. É válida, também, outra definição de Carolina para favela, a qual aliás intitula um de seus livros: A favela é um quarto de despejo; os barracos de madeira são lugares de passagem, a favela é quase um não lugar, pois tão logo a superabundância material da cidade se insinue com seus processos de gentrificação, ou simplesmente com a construção de uma nova avenida ou viaduto, os favelados serão despejados, irão para outra favela ou construirão uma nova.

Figura 3 - Carolina de Jesus: a escritora. Fonte: https://www.geledes.org.br/literariedade-daobra-de-carolina-de-jesus-um-reconhecimento-necessario/. Acesso em 20/12/2019.

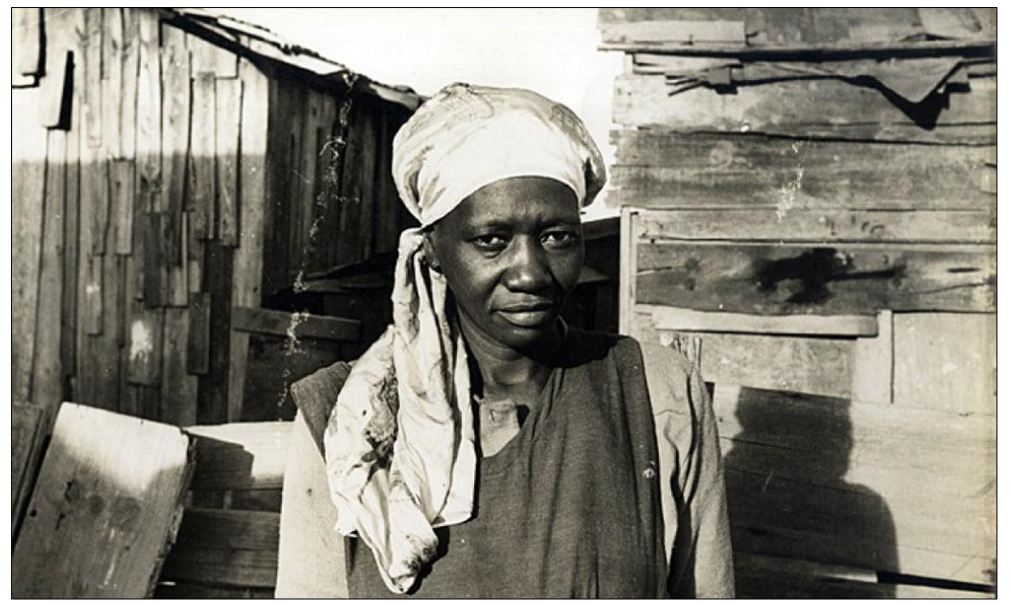

Aqui, a crítica pós-humanista inspirada pelo antropoceno talvez se desloque a outro patamar. Conforme Marco Amiero e Massimo De Angelis, o conceito capitoloceno é mais apropriado do que o de antropoceno. Os traços do capitoloceno não são apenas geológicos e climáticos. Eles se inscrevem diretamente no corpo humano, como marcas da exploração, subordinação, opressão e desigualdade. O capitoloceno atua também por meio de materialidades que o filósofo camaronês Achille Mbembe chama de necropolítica: uma nova forma de soberania que, mais do que definir o direito das nações de se autogovernarem, dita quem pode viver e quem deve morrer. Como a teoria do emaranhamento humano-coisas pode pensar os regimes de aprisionamento da população pobre? Como essa teoria pode contribuir para entender os emaranhamentos acionados por estruturas coloniais e racistas do mundo contemporâneo? 
IH - Por que é tão difícil para as pessoas escaparem da pobreza? Pode-se dizer que é o capitalismo, ou a globalização, ou o colonialismo, ou o racismo. Estamos acostumados a atribuir a pobreza a tais causas. Precisamos de algo para culpar. E muitas vezes culpamos as estruturas e as instituições, e às vezes a ditadores e a presidentes. $\mathrm{Ou}$ culpamos a história. Portanto nos referimos a conceitos exauridos e às mínimas soluções que esses conceitos comportam. Não sei se ajudaria a Carolina Maria de Jesus eu afirmar que sua situação é causada por esses conceitos gerais e abstratos. O que ela precisa, presumo, é de soluções. Encontrar uma solução envolve trabalhar do zero para descobrir os emaranhados biomateriais que a prendem. Envolve lidar com especificidades. Como eu disse antes, a armadilha da pobreza é apenas parte de uma série de forças interligadas que se combinam para tornar a mobilidade social praticamente impossível. Encontrar soluções significa mapear os múltiplos emaranhados interligados e lidar com soluções que cruzam especialidades, departamentos e domínios. Os processos que descrevemos como neoliberais não fazem isso bem. Comecei a pensar recentemente que a ascensão dos ditadores no mundo moderno pode ser vista como uma resposta à extrema conexão e emaranhamento das coisas, criando uma ideia de que a única solução para as complexidades parece ser um governo central forte. Um governo central forte na China tirou milhões da pobreza, mas às custas dos direitos humanos. Essas formas opressivas de governo estão se espalhando por todo o mundo. Parece que não temos nada para combatê-las. Na minha opinião, é porque perdemos de vista no Ocidente a ideia do Estado como provedor; o neoliberalismo acabou com isso. O que é necessário são estados benignos poderosos, com as energias e os recursos necessários para analisar as especificidades de vidas como a de Carolina e encontrar soluções comprovadas que possam ser aplicadas com compaixão. Essas soluções precisam olhar além de causas e rótulos específicos, como capitalismo e globalização; elas precisam libertar-se de tais preconceitos ou conceito prévios, a fim de identificar processos inter-relacionados específicos, mesmo em larga escala, que possam ser alterados.

MTB e LMF - Assumindo que vivemos sob uma perspectiva fragmentada e, muitas vezes, "especializada", fechamo-nos num mundo próprio, como se estivéssemos num grande "videogame". Mas a diferença é que todos os nossos atos gerados a partir dessa visão fragmentada têm consequências na Grande Realidade. Tais consequências podem afetar a vida de todo o planeta e as gerações futuras. Bauman (2000) argumentou que o tempo se tornou um problema de hardware. Os humanos, pois, podem reinventá-lo, apropriá-lo, usá-lo e controlá-lo. Assim é que, ao contrário do espaço, o tempo no Ocidente é pensado como algo que pode ser mudado e manipulado; tornou-se um fator disruptivo na dinâmica espaço-tempo. Nesse sentido, o problema da percepção parece um caminho bastante interessante a seguir. Mais especificamente, a questão central elaborada por Capra (1997) em The Web of Life: por mais alto que seja o esforço empreendido, a maioria da população não está com seus respectivos "modelos mentais" adequadamente preparados para ver as conexões entre a vida e os conceitos da Nova Ciência. Ainda estamos muito apegados à estrutura de pensamento criada pela ideia de ciência do início do século XX. Você acha que o surgimento do pensamento sistêmico representou uma profunda revolução na história do pensamento científico ocidental, que ainda acredita fundamentalmente no paradigma cartesiano, ou seja, que o todo pode ser entendido inteiramente a partir das propriedades de suas partes, reduzindo-as em partes ainda menores? É realmente uma ruptura completa com esse paradigma? A equação que temos que resolver não parece simples: como podemos atualizar nossa maneira de pensar e ver o mundo com base nas estruturas mentais alinhadas com a ciência (no seu sentido amplo) do limiar do século XXI? 
IH - Sim, obviamente um dos aspectos principais da teoria do emaranhamento humano-coisas é que tudo está conectado; não há sistemas fechados. Essa abertura de sistemas, e de fato a própria crítica de sistemas como modelo, produz dificuldades reais na análise. Tentei argumentar que existem soluções metodológicas que podem ser buscadas em, por exemplo, análise de redes, assim como em novas publicações que nos fornecerão métodos para examinar emaranhados biomateriais diacrônicos. Mas ainda não está claro para mim se diferentes escalas de análise exigem argumentos teóricos diferentes. Certamente teorias que lidam com partículas subatômicas são fascinantes como possíveis analogias para a ação social, mas não está claro se o comportamento das partículas subatômicas é o mesmo que impacta as tendências da escala social. Parece-me que as teorias que pertencem a diferentes escalas de análise talvez precisem ser diferentes, mesmo que elas se informem reciprocamente de maneira produtiva. Escritores como Deleuze e Guattari foram profundamente influenciados pelos novos paradigmas que emergiam na física, e Alfred North Whitehead desenvolveu teorias gerais de processo influenciado pelas atuais teorias do eletromagnetismo. Tudo isso se mostra muito frutífero e, em meu novo trabalho sobre materiais como forças, ondas e fluxos, sou igualmente influenciado por essas tendências, mas também comecei a questionar nossa dependência dessas metáforas e sinto que explorar as diferenças entre escalas também é importante; a grande teoria universal pode ser uma miragem.

MTB e LMF - Desde Sidney Brenner surgiu uma nova linguagem destinada a entender sistemas de vida complexos e altamente organizados. Cada cientista lhes deu um nome diferente. Alguns deles são: "teoria dos sistemas dinâmicos", "teoria da complexidade", "dinâmica não linear", "dinâmica de rede", "fractais", "estruturas dissipativas", "auto-organização" e "redes autopoiéticas". Essas abordagens para entender a vida são realizadas por pesquisadores notáveis e suas equipes em todo o mundo, como por exemplo, Ilya Prigogine na Universidade de Bruxelas; Humberto Maturana, na Universidade do Chile; Francisco Varela na École Polytechnique de Paris; Lynn Margulis, da Universidade de Massachusetts; Benoit Mandelbrot na Universidade de Yale; Stuart Kauffman no Instituto de Santa Fé; Sidarta Ribeiro na Universidade Federal do Rio Grande do Norte, e podemos incluir você atuando na Universidade de Stanford.

Parece ser consenso entre esses pesquisadores, de diferentes áreas do saber, que a concepção de sistemas vivos como redes é o que proporcionaria uma nova perspectiva sobre as chamadas hierarquias da natureza. A noção de conhecimento científico (e até a própria vida) como uma rede de concepções e modelos, na qual nenhuma parte é mais fundamental do que a outra, foi formalizada na física, na década de 1960, por Geoffrey Chew, em sua filosofia de inicialização (teoria bootstrap das interações fortes). O bootstrap não apenas abandona a ideia de blocos de construção fundamentais, como também não aceita entidades fundantes, e tampouco constantes, leis e equações fundamentais. $\mathrm{O}$ universo material é visto como uma rede dinâmica (ou redes) de eventos interrelacionados. Nenhuma das propriedades de qualquer parte dessa rede é fundamental; todas elas resultam das propriedades das outras partes, e a consistência geral de suas inter-relações determina a estrutura de toda a rede.

A primeira e mais óbvia propriedade de qualquer rede é sua não linearidade. Ela se estende em todas as direções. Assim, relacionamentos em um padrão de rede são relações não lineares. Foi no início dos anos 1970 que o filósofo norueguês Arne Naess propôs uma distinção entre "ecologia rasa" e "ecologia profunda". Capra, seguindo esse pensamento, argumenta que a "ecologia superficial" é considerada antropocêntrica ou centrada no humano. Ela vê os seres humanos como acima ou fora da natureza, como fontes de toda valoração, atribuindo apenas um valor instrumental ou "útil" à natureza. A "ecologia profunda", por outro lado, não separa os seres humanos, ou qualquer outra 
coisa, do ambiente natural. Ela vê o mundo não como uma coleção de objetos isolados, mas como um fenômeno de rede que é fundamentalmente interconectado e interdependente. Isso equivale ao que Tim Ingold, na antropologia, chama de "ambiente sem objetos". A ecologia profunda reconhece a imanência de todos os seres vivos e vê os seres humanos como apenas uma vertente específica na teia da vida. Como você vê o papel da Arqueologia nessa discussão? Como escapar das hierarquias humanas, que são estruturas de dominação e controle absolutamente rígidas, para analisar formas muito diferentes de ordem multinível, tais como encontramos na natureza? Você pensa que esse conceito de "teia da vida", tanto quanto a compreensão dos emaranhados biomateriais, proporcionariam uma nova perspectiva sobre as chamadas hierarquias da natureza? Você vê esse assunto relacionando-se a sua teoria sobre o emaranhado humano-coisas?

IH - Como indiquei antes, distinguiria os emaranhados das redes. Não vejo os emaranhados apenas como um conjunto de ligações entre nós. Ao contrário, os nós são produzidos dentro dos processos e fluxos de vários tipos de energia, e os diferentes fluxos são capturados um no outro, fortalecendo-se ou se restringindo mutuamente. A maioria das teorias da complexidade e dos sistemas dinâmicos visa a encontrar algum modelo matemático abrangente, elegante em sua simplicidade, que explique até o mais complexo dos sistemas. Não estou interessado em tais objetivos. O estudo dos emaranhados é ou deveria ser profundamente histórico - a exploração das dependências, dos caminhos pelos quais temos viajado para chegar a um determinado ponto no tempo. Então eu gosto das ideias de "filosofia de inicialização" e "ecologia profunda". Para mim, a tarefa da arqueologia é documentar o surgimento de caminhos que têm raízes profundas e que ainda hoje nos afetam. Quando dirigimos um carro, raramente pensamos em como ele depende do desenvolvimento da roda que começou há 6 mil anos. Nos vemos como "modernos" e livres de restrições, quando na verdade a maioria das coisas que dizemos e fazemos tem histórias profundas e trazem uma bagagem acumulada por milênios. E a arqueologia também tem o papel de documentar as maneiras pelas quais nossas vidas hoje são tão materialmente quanto socialmente entrelaçadas. Como disciplina, sentamo-nos nas humanidades, ciências sociais e ciências naturais e materiais. Desse ponto de vista, podemos contribuir para a compreensão dos emaranhados biossociomateriais; as maneiras pelas quais corpos, coisas, materiais, desejos e sociedades dependem um do outro.

MTB e LMF - Em última análise, diríamos que a percepção da ecologia profunda se relaciona, de alguma forma, às práticas espirituais, religiosas. Quando a concepção de espírito humano é entendida como modo de consciência em que coletivos criam um senso de pertencimento e de conexão com o cosmos, fica claro que a percepção ecológica é espiritual em sua imanência. Não é de surpreender, portanto, que a nova visão do surgimento da realidade se baseie nessa percepção ecológica profunda e se coadune com a chamada filosofia perene das tradições espirituais, quer falemos sobre a filosofia e a espiritualidade dos místicos do Judaísmo, Cristianismo, Islamismo ou Budismo, quer pensemos, guardadas as devidas especificidades, sobre as práticas espirituais fundadas nas filosofias da ancestralidade, como algumas das tradições africanas e ameríndias. Como você vê o crescente interesse na evolução das capacidades religiosas e a importância de interpretar aspectos religiosos do registro arqueológico? Como se dão as relações entre humanos, coisas e o sagrado?

IH - No meu trabalho em Çatalhöyük, eu me pego pensando muito em religião e editei 4 livros recentemente sobre vários aspectos da religião presente nesse sítio arqueológico. Então a pergunta que vocês me fazem muito me interessa. Interessei-me por tradições ascéticas que rejeitam materialismos e parece-me que temos muito a 
aprender com o Budismo, o Hinduísmo inicial e com muitas sociedades indígenas, se quisermos reverter o consumismo material que envolveu o mundo. A questão de por que os humanos precisam de coisas para se aproximar do divino é obviamente fundamental aqui, e passei muito tempo tentando encontrar uma resposta. No meu livro on-line (HODDER, 2016), eu tenho um capítulo no qual defendo que a religião é, em última análise, alcançar "o além”, o inefável. Esse além não é imaginário. É real porque todos os emaranhados se estendem a relacionamentos e dependências enormemente complexos que nós, como atores individuais, podemos ter poucas chances de controlar. O que podemos fazer, no entanto, é pegar exemplos dessas coisas e manipulá-las na esperança de influenciar outras coisas. Portanto, o interessante da religião é que ela entende a conexão das coisas e usa essa conexão para influenciar emaranhados que se estendem para o além. Assim, quando beijamos um ícone ou comemos e bebemos o corpo e o sangue de Cristo, ou tocamos uma pedra sagrada ou visitamos um edifício sagrado, estamos certos ao pensar que estamos em contato com o além. Nós de fato estamos, porque todos os enredos se estendem ao inefável. Sempre há um algo "mais" em uma coisa. Ela sempre aponta para além de si mesma e para outras coisas, eventos, emoções, histórias. Então, em certo sentido, todas as coisas são religiosas. Elas nos levam além do momento presente e, ao mesmo tempo, nos fixa nesse momento. As coisas humanas oferecem a possibilidade de ir além.

MBT e LMF - Pode-se considerar a arqueologia, portanto, uma ciência hipercomplexa, mais árdua que a física e a química, pois ela tende a conversar mais com seres humanos, e não com fótons e radicais sulfeta, por exemplo. Retomemos Bauman: ele argumenta que a "conquista do espaço" passou a significar máquinas mais rápidas. $\mathrm{O}$ movimento acelerado significa espaço maior, e acelerar os movimentos é o único meio de ampliar o espaço. Assim, a expansão espacial era o nome do jogo, e o espaço era a aposta; o espaço era o valor e o tempo era a ferramenta. Para maximizar o valor, era necessário aprimorar os instrumentos; grande parte da "racionalidade instrumental", como Max Weber sugeriu, era o princípio operativo da civilização moderna, focado em projetar maneiras de maximizar tarefas mais rapidamente, eliminando o "improdutivo", o tempo ocioso, vazio e tido como desperdiçado.

Para contar a mesma história em termos de efeitos, em vez de meios de ação, concentrou-se em preencher mais densamente os espaços com objetos. No limiar da conquista moderna do espaço, Michel De Certeau declarou que o poder atua sobre territórios e fronteiras: as armas do poder, da estratégia, são a classificação, o delineamento e a divisão; e a forte dependência da certeza do mapeamento. Pode-se dizer que a diferença entre os fortes e os fracos reside entre um território moldado na imagem do mapa, bem guardado e controlado, e um território aberto à intrusão, redesenhos, despejo e recarga dos mapas. Nesse ponto, é impossível não pensar novamente na ficção especulativa distópica. Especialmente naquela que reconfigurou a cidade utópica, a Nova Atlântida de Francis Bacon reinventada, um paraíso artificial murado, imerso em superabundância tecnológica, onde vive uma elite autocrática, malthusiana, a controlar, com robôs e satélites, os outros humanos, os "sub-humanos" concentrados em guetos e favelas, cuja proliferação exponencial se deve à migração em massa ocasionada pelo colapso ambiental.

Você aborda esses assuntos mais densamente em Where are we heading? (2018). Recentemente, surgiu a geoengenharia, com a intenção deliberada de desenvolver em larga escala tecnologias para intervenção nos sistemas naturais da Terra a fim de controlar as mudanças climáticas. Como você analisa essa emergência? A questão principal parece ser que essa iniciativa pode equilibrar uma parte da Terra onde o dinheiro é investido para esse balanceamento e, ao mesmo tempo, desequilibrar outras 
partes mais pobres da Terra que não terão recursos para criar uma contra-proteção tecnológica. Se pensarmos que um país desenvolvido que sofre ondas de calor investe em tecnologias para criar chuvas em sua região, isso poderia aumentar a seca em países pobres, por exemplo. Você poderia relacionar esses tópicos com suas ideias sobre dependência de caminhos e formas de direcionalidade?

IH - Concordo inteiramente com a direção da pergunta de vocês e discuto essas questões, como vocês mencionam, no livro Where are we heading? (2018). Investir na geoengenharia como solução para as mudanças climáticas globais é apenas uma continuação do que sempre fizemos como espécie. Quando as coisas ficam difíceis, os fortes investem em tecnologias para resolver problemas. Nesse livro, dei o exemplo de fiadores de algodão no norte da Inglaterra, que engendraram a revolução industrial mecanizando as máquinas de fiar algodão. $\mathrm{O}$ resultado foi uma riqueza massiva para alguns, mas também uma grande pobreza para outros, à medida que as pessoas eram retiradas das áreas rurais para povoar as novas fábricas de algodão. As pessoas logo começaram a se revoltar contra as máquinas, quebrando-as em tumultos. Hoje talvez precisemos nos levantar novamente contra as tecnologias modernas que destroem vidas e criam pobreza e miséria em escala global. Fiquei muito desapontado com o fato de que a maior parte da retórica dos movimentos que protestavam e protestam contra as mudanças climáticas se concentrou nas energias renováveis, e não nos vícios do consumismo que criaram a necessidade de suprimentos infinitos de energia. Muitas das soluções de geoengenharia propostas para lidar com as mudanças climáticas são assustadoras em seu escopo e impacto. No entanto a direção que estamos seguindo parece ser a mesma de sempre desde que um humano usou a primeira ferramenta de pedra.

MTB e LMF - Sua resposta nos leva a pensar sobre a alteridade. Claude LéviStrauss (1996) sugeriu, no livro Tristes Trópicos, que apenas duas estratégias foram implantadas na história humana sempre que surgiu a necessidade de lidar com a alteridade: a antropoêmica e a antropofágica. A primeira consistia no "vômito", expelindo-se os outros, vistos como incuravelmente estranhos e alheios, barrando-se o contato físico, o diálogo, as relações sociais e todas as variedades de commercium, comensalidade ou connubium. As variantes extremas da estratégia antropoêmica são, como sempre, encarceramento, deportação e assassinato. As formas modernizadas, aprimoradas e "refinadas" da estratégia "êmica" são a separação espacial, os guetos urbanos, o acesso seletivo a espaços e o impedimento seletivo de usá-los.

A segunda estratégia, a antropofágica, consiste em ingerir, devorar corpos e espíritos estranhos, para que possam ser feitos, por meio do metabolismo, idênticos e não mais distinguíveis do corpo que ingere. Essa estratégia assumiu uma variedade igualmente ampla de formas: do canibalismo à assimilação forçada; cruzadas culturais; guerras aos costumes locais; assimilação de calendários, cultos, dialetos; além, é claro, da disseminação de preconceitos. Se a primeira estratégia visava o exílio ou aniquilação dos outros, a segunda visava a suspensão ou aniquilação da alteridade. Como você lida com esses assuntos?

IH - Certamente vemos essas duas estratégias em ação hoje nas maneiras pelas quais diferentes nações lidam com a imigração e a alteridade. Por um lado, países como a França e a Turquia argumentam que todos os imigrantes devem se tornar franceses ou turcos e as diferenças culturais dentro do país são minimizadas, enquanto nos Estados Unidos e na Grã-Bretanha o foco é permitir e promover a diferença, mesmo que isso leve ao conflito e ao gueto. Já no Neolítico de Çatalhöyük, vemos uma sociedade com regras internas muito fortes, embora, na origem, o assentamento tenha sido provavelmente formado por uma variedade de comunidades diferentes. A uniformidade tem seu lado 
sombrio. Há evidências de violência ritualizada e controlada que, no entanto, não levaram à morte. Mas quando os habitantes morriam, eles geralmente eram enterrados em casas. Em alguns casos, foram encontrados indivíduos sendo enterrados fora da casa, em áreas de esconderijo ou refugo. E nesses casos, os restos humanos geralmente mostram traços de incapacidade ou doença e desfiguração a longo prazo. Tudo isso sugere que controles internos fortes foram acionados, excluindo-se aqueles que não se enquadravam nas categorias normalizadas. Certamente parece possível para os arqueólogos mapearem essas diferentes linhas de afiliação ao longo do tempo. 


\section{REFERÊNCIAS}

BAUMAN, Z. Liquid Modernity. Cambridge: Polity Publisher, 2000.

BARAD, K. Meeting the Universe Halfway: Quantum Physics and the Entanglement of Matter and Meaning. Durham: North Carolina, 2007.

CAPRA, F. The Web of Life: A New Scientific Understanding of Living Systems. Anchor Academic Publisher, 1997.

CHEW, G.; FRAUTSCHI, S. Principle of Equivalence for all Strongly Interacting Particles within the S-Matrix Framework. Physical Review Letters, 7 (10), p. 394-397, 1961.

CRUTZEN, P. Geology of Mankind. Nature 415 (23), 2002.

DELEUZE, G. Post-Scriptum sobre as Sociedades de Controle. Conversações (1972-1990). Rio de Janeiro, Paz e Terra, 1992.

FOUCAULT, M. Isto não é um cachimbo. Rio de Janeiro: Paz e Terra, 1988.

GEERTZ, C. Negara. The Theatre State in Nineteenth-Century Bali. Princeton University Press, 1980.

GONZÁLEZ-RUIBAL, A. Hacia Otra Arqueología: diez propuestas. Complutum, (23): 2, 103-116, 2012.

HODDER, I. The Spatial organization of culture. New approaches in archaeology. Duckworth: University of Michigan, 1978.

HODDER, I. Symbols in Action: Ethnoarchaeological Studies of Material Culture. Cambridge: Cambridge University Press, 1982.

HODDER, I. Symbolic and Structural Archaeology. Cambridge: Cambridge University Press, 1982.

HODDER, I. Reading the Past: Current Approaches to Interpretation in Archaeology. Cambridge: Cambridge University Press, 1986.

HODDER, I. The Archaeological Process: An Introduction. Wiley-Blackwell: John Wiley and Sons Inc., 1999.

HODDER, I. Entangled: An Archaeology of the Relationships between Humans and Things. WileyBlackwell: John Wiley and Sons Inc., 2016.

HODDER, I. Where Are We Heading? The Evolution of Humans and Things. New Have and London: Yale University Press, 2018.

LÉVI-STRAUSS, C. Tristes Trópicos. São Paulo, Companhia das Letras, 1996.

NEGRI, A.; HARDT, M. Empire. Cambridge, Harvard University Press, 2000.

SHANKS, M., TILLEY, C. Re-constructing Archaeology. Theory and Practice. Abingdon: Routledge, 1982.

VAN DYKE, R; BERNBECK, R. (eds.). Subjects and Narratives in archaeology. Colorado, University of Colorado Press, 2015

VIVEIROS DE CASTRO, E. Transformação na Antropologia, Transformação da Antropologia. Mana, (18): 1, 151-171, 2012. 